to find identical conditions with respect to oxygen and other dissolved gases. Moreover the temperature limits in which fish, especially the Salmonidae, can survive are much narrower than with terrestrial animals; the variation in temperature for successful work is still more limited when considering rapid growth and reproduction.

Therefore, when this breeding project has produced certain desired results at a given station or in certain waters, the adoption of the same procedure at other places will not necessarily produce the same results. Nevertheless the results of breeding experiments should tend to establish general principles which may guide the commercial trout raiser in improving his stock with the view to increasing its market value.

Unfortunately the Committee knows of no establishment, public or private, where such experiments can be brought to a conclusion unless the legitimate work for which such stations were established is practically abandoned. It is estimated that an experiment station suitable for the execution of this breeding project would cost $\$ 50,000$, exclusive of the cost of land and water rights.

With the steady increase in the population of this country and the gradual but inevitable decrease in its fisheries resources, fish culture and fish breeding as a private enterprise will increase in importance and the need of an experiment station will become more and more apparent.

\title{
BREEDING SADDLE HORSES ON LINES FOR IMPROVEMENT AND DEVELOPMENT.
}

By I. B. NaLl, Secretary American Saddle Horse Breeders' Association, Louisville, Ky.

\section{POSSIBILITIES OF IMPROVEMENT.}

The caption at once leads me to the meat of the subject, as it suggests the question, what is to be improved and what to be developed? If we compare the splendid saddle horse of the present time'with the beasts of burden known as such a century ago we have an idea of the possibilities of improvement. If we compare the bold way the present day saddle horse has of going with the low carriage and slow pace of his progenitor of early times, we get an idea of what has been done by development of his gaits.

\section{PRESENT DEMANDS.}

It is by improvement and development that breeders of intelligence are raising the standard of this horse to meet the demands of buyers. That demand, let it be said, has progressed quite as rapidly as has the process of improvement. Indeed at one time it looked as if the requirements for a saddle horse in the best market in the country had run quite away from the breeders in the sections of the 
country where now are to be found the greatest herds of the most fashionable types of the breed. At the time referred to breeders were paying more attention to gaits than to style, action, and size, while demand was running rather to gaits, but narrowing to the three natural gaits-walk, trot, and canter.

\section{A MISTAKE IN TRAINING.}

Therefore, when the breeder and trainer were educating their horses in the five gaits, they were doing just what their customer did not want done. In other words while the horsemen of Kentucky, Missouri, Tennessee and other Western States were still wedded to the rack and running walk, the Fastern market made no such demand, and, indeed, regarded these gaits as very objectionable, and looked to other markets for their mounts.

However, when Westerners opened their eyes, they had to make no change in breeding. They simply changed their method of training. When the Connecticut man found himself overstocked with shoe pegs he just sharpened the other end and sold them for oats. Our horseman, finding a dull market for long-tail, five-gaited horses, simply docked them and left out of their training two gaits. Thus those who depend on the Eastern market are breeding for high style and finish with a bold trot, an easy canter, and a swift walk. The result is satisfactory to all, and now the Kentucky or Western saddle horse is winning laurels at the New York and other Eastern shows in all the saddle classes.

\section{METHODS OF IMPROVEMENT.}

Improvement is carefully made by the introduction of the blood of such outside families as contributes to the requisites of good size, high finish, springy gaits, and bloodlike appearance. Breeders are careful not to go so far as to lose the basic influence of the old foundations. This transition period is not over, but the process is in operation and results being observed most scrupulously as the younger specimens are being led or ridden into the show rings at fairs hereabouts or in the sales rings in the East.

Fear has been expressed by some of the old-time breeders that the introduction of the Mambrino and other out-crosses would destroy the type of the saddle horse and soon result in a change from the horse noted for style and symmetry to one of more rapid and bolder action, but of rugged form. No doubt, if care is not taken in the selection of the out-cross, this will be the result, but the show rings of this year prove that certain of these out-crosses have had the desired result without as yet detracting from the beauty of the type. There may be instances of failure too, but such are not likely to be exhibited and will be left out in future selection for breeding purposes. It is the show ring and the sale ring that will test the success or failure of breeding for improvement and development. The present tendency seems to be toward a commingling of the blood of 
Denmark with the Chief strains. Some breeders think it should be obtained by the use of Denmark sires on Chief mares and others that the sources of improvement should be expected from the reverse course of breeding. This is the problem being worked out by breeders. From all appearances it seems at present a mooted question. One thing is certain, that there have been shown in the past two or three years some splendid specimens attesting the claim that the Chief blood should be introduced through the sire, but it is noticeable that it comes through a strain backed up strongly on the dam's side by Denmark blood.

In conclusion I will say, as I am only asked for a brief statement, that many breeders are securing stallions of the Chief cross while others are introducing this blood through the dams, still keeping the Denmark blood on top in the sire, we shall see with what result in the next year or two.

Horses being prepared for the Eastern markets are trained to the walk, trot, and canter gaits, while the Westerner and Southern planter still demands his running walk and rack.

\title{
THE AMERICAN TROTTING ASSOCIATION AND ITS METHODS.
}

\author{
By W. H. KNIGHT, Secretary of the Association, Chicago, Ill.
}

A little over one hundred years ago a gray horse known as "Messenger" was imported to this country from England and it is almost entirely his descendants that represent the trotting horse of today and particularly through the families of "Hambletonian No. 10" and "Mambrino Chief No. 11," who were his great grandsons.

As the number of horses that could show speed at a trotting gait increased, trotting tracks, or parks as they were sometimes called, were built where matched races were trotted and finally class races were put upon the program. The interest so increased that public meetings were given, but it is only within the past fifty years that it has developed such proportions as to attract much attention.

On account of abuses that crept into the sport, honest lovers of the horse found it necessary to form an association for its regulation and protection, so in February, 1870, a voluntary association was made under the laws of Connecticut, known as the National Trotting Association, composed of the leading parks of the country and a code of laws for the government of all was adopted as the surest means of correcting the abuses and of elevating and protecting the character and standing of the American trotting turf. Its first President was Gov. Amasa Sprague of Rhode Island, a wealthy, influential lover of the horse and of honest racing. At the time of its foundation there were less than 100 members, but it grew rapidly in numbers and influence and to-day has over 500. 